\title{
Genetic regulators of energy balance
}

\begin{abstract}
Objective: Polymorphic variations in humans are supposed to be responsible for inter individual differences in susceptibility to multifactorial disorders like obesity. Genetic variants of the melanocortin-4 receptor gene (MC4R), agouti related protein (AGRP) and prboopiomelanocortin (POMC) are reported to be associated with obesity. Therefore we tried to see the association of these genes with obesity in north Indian population.

Methods: The genotyping was done with Taq man probes and statistical was performed by SPSS software version 19.

Results: The CC (homozygous) genotype of MC4R rs17782313, ( $p=0.02 ; \mathrm{OR}=1.7)$ and CT (heterozygous) genotype of POMC rs1042571, $(p=0.01$; OR=1.6) SNPs were significantly associated with obese individuals $\left(\mathrm{BMI} \geq 30 \mathrm{~kg} / \mathrm{m}^{2}\right)$. However, no association of AGRP rs34123523 ( $p=0.23 ; \mathrm{OR}=1.2)$ was seen with $\mathrm{BMI} \geq 30 \mathrm{~kg} / \mathrm{m}^{2}$.
\end{abstract}

Keywords: obesity, genetic variants

\author{
Volume 4 Issue 4 - 2017
}

\author{
Neena Srivastava,' Apurva Srivastava,' \\ Pranjal Srivastava, ${ }^{2}$ Nimisha Srivastava ${ }^{3}$ \\ 'Department of Physiology, King George's Medical University, \\ India \\ ${ }^{2}$ Darbhanga Medical College and Hospital, India \\ ${ }^{3}$ Sikkim Manipal Institute of Medical Sciences, India
}

\author{
Correspondence: Neena Srivastava, Department of \\ Physiology, King George's Medical University, India, Pin-226 024, \\ Tel +9l 94 I 502 4024, +9l 5222745555 ; \\ Email drneenasrivastava@hotmail.com
}

Received: April 24, 2017 | Published: August 0I, 2017

\section{Introduction}

Obesity has received considerable attention as a major health hazard, which is a complex disorder resulting from the interactions of a wide variety of genetic and environmental factors. Overweight and obesity are associated with premature death through increased risk of many chronic diseases including type 2 diabetes (T2D), cardiovascular disease and cancer. ${ }^{1}$ In addition, obesity also increases adverse cardiac events indirectly mediated through dyslipidemia, hypertension, glucose intolerance and sleep disorders. It has been hypothesized that polymorphic variations in humans may be responsible for interindividual differences in susceptibility to multifactorial disorder like obesity. The studies that looked for genes that predispose to common obesity were based on candidate genes, where the focus was on genes with a suspected role in the regulation of metabolism and food intake. The recent emergence of the genome-wide association studies (GWAS) has led to further breakthroughs in gene identification and now nine loci are recognized to be involved in Mendelian forms of obesity along with 58 loci contributing to polygenic obesity. In the present study, we have attempted to investigate in Northern India, the association of few recent loci identified in GWAS and candidate gene studies, with risk of BMI linked obesity and obesity linked comorbities like Type 2 Diabetes and CardioVascular Disease. Further, we also aimed to explore high order gene-gene interactions using multidimensional statistical approaches to evaluate risk of obesity. Obesity and the associated risks are rising global health burden. Numerous variations in genes may contribute to the pathogenesis of obesity. The physiological pathways related to appetite are complex and involve the mixing of short-term satiety signals from the gut to the brain along with longer-term homeostatic systems which grip the integrated signaling of POMC, AGRP, and MC4R systems and risk an individual to obesity. ${ }^{2}$ Agouti related protein (AGRP) is an evolutionary conserved gene mainly located in arcuate neurons that co-express neuropeptide Y (NPY) and is also a strong negotiator of regulation of energy balance. ${ }^{3}$

Melanocortin signaling in the hypothalamus plays a vital role in the control of energy homeostasis. These peptides signal to downstream target neurons in the lateral hypothalamus that express the melanocortin receptor MC4R with consequential decrease in food intake and increase in energy expenditure. ${ }^{4}$ Rare mutations in the POMC (proopiomelanocortin) gene (Cytogenetic Location: 2p23.3) cause early-onset obesity in humans though the influence of common polymorphisms in POMC on obesity phenotypes in less extreme individuals is indistinct. ${ }^{5}$ In this study relation of MC4R (rs17782313, rs 17700633), AGRP (rs34123523) and POMC (rs1042571) and their association with obesity $\left(\mathrm{BMI} \geq 30 \mathrm{~kg} / \mathrm{m}^{2}\right)$ in North Indian population was observed. The analysis revealed that the $\mathrm{CC}$ (homozygous) genotype of MC4R rs17782313, $(p=0.02 ; \quad \mathrm{OR}=1.7)$ and CT (heterozygous) genotype of POMC rs1042571, $(p=0.01$; OR=1.6) SNPs were significantly associated with obese individuals (BMI $\geq 30 \mathrm{~kg} /$ $\mathrm{m}^{2}$ ). However, no association of AGRP rs34123523 ( $p=0.23$; $\mathrm{OR}=1.2)$ was seen with $\mathrm{BMI} \geq 30 \mathrm{~kg} / \mathrm{m}^{2}{ }^{6}$ The association of the SNP MC4R rs17782313 with obesity has previously been investigated in "European-American" children and studies have reported significant associations. ${ }^{7}$ The SNP was also found significantly associated with obesity in adult Chinese, ${ }^{8}$ central obesity in Chinese children, ${ }^{9}$ Danish, ${ }^{10}$ "African" and "European-American" populations. ${ }^{11} \mathrm{MC} 4 \mathrm{R}$ and POMC variants have influence on obesity and contribute to the variance in body mass index (BMI) in Europeans and East Asians ${ }^{12}$ Studies in two ethnic specific polymorphisms suggest that slight differences in food preference in carriers of the rare AGRP alleles (T/T and Ala67Thr in blacks and whites, respectively) could over time result in lower adiposity. ${ }^{13}$ In this study of POMC rs1042571 CT heterozygote and $\mathrm{BMI} \geq 30 \mathrm{~kg} / \mathrm{m}^{2}$ was significantly associated $(p=0.01$; $\mathrm{OR}=1.6$ ) with higher $\mathrm{BMI} \geq 30 \mathrm{~kg} / \mathrm{m}^{2}$ and results are in agreement with those reported by Krude $\mathrm{H}$ et al. ${ }^{5}$ In view of the fact that obesity is caused by perturbations of the balance among food intake and energy expenditure, all along with social-environmental factors, which are regulated by a complex physiological system that requires the incorporation of several peripheral signals and central coordination in the brain, the outcome of the study implies that polymorphisms in MC4R, and POMC have a function in the regulation of food intake, energy expenditure and preference for specific food items which may result in obesity. North Indian population is presented in this report for the first time suggesting that naturally occurring mutations in MC4R, AGRP and POMC can make an individual to be at risk of obesity. The results of the study may significantly add to our knowledge and understanding of role of genetic factors in progression of obesity.

\section{Acknowledgements}

None. 


\section{Conflict of interest}

Author declares that there is no conflict of interest.

\section{References}

1. Kopelman P. Health risks associated with overweight and obesity. Obes Rev. 2007;8(1):13-17.

2. Badman MK, Flier JS. The gut and energy balance: visceral allies in the obesity wars. Science. 2005;307(5717):1909-1914.

3. Klovins J, Haitina T, Fridmanis D, et al. The melanocortin system in Fugu: determination of POMC/AGRP/MCR gene repertoire and synteny, as well as pharmacology and anatomical distribution of the MCRs. Mol Biol Evol. 2004;21(3):563-579.

4. Yeo GS, Farooqi IS, Challis BG, et al. The role of melanocortin signalling in the control of body weight: evidence from human and murine genetic models. QJM. 2000;93(1):7-14.

5. Krude H, Biebermann H, Schnabel D, et al. Obesity due to proopiomelanocortin deficiency: three new cases and treatment trials with thyroid hormone and ACTH4-10. J Clin Endocrinol Metab. 2003;88(10):4633-4640.

6. Srivastava A, Mittal B, Prakash J, et al. Evaluation of MC4R [rs17782313, rs17700633], AGRP [rs3412352] and POMC [rs1042571] Polymorphisms with Obesity in Northern India. Oman Med J. 2014;29(2):114-118.
7. Zobel DP, Andreasen CH, Grarup N, et al. Variants near MC4R are associated with obesity and influence obesityrelated quantitative traits in a population of middle-aged people: studies of 14,940 Danes. Diabetes. 2009;58(3):757-764.

8. Cheung CY, Tso AW, Cheung BM, et al. Obesity susceptibility genetic variants identified from recent genome-wide association studies: implications in a chinese population. $J$ Clin Endocrinol Metab. 2010;95(3):1395-1403.

9. Xi B, Cheng H, Shen Y, et al. Study of 11 BMIassociated loci identified in GWAS for associations with central obesity in the Chinese children. PLoS One. 2013;8(2):e56472.

10. Qi L, Kraft P, Hunter DJ, et al. The common obesity variant near MC4R gene is associated with higher intakes of total energy and dietary fat, weight change and diabetes risk in women. Hum Mol Genet. 2008;17(22):3502-3508.

11. Liu G, Zhu H, Dong Y, et al. Influence of common variants in FTO and near INSIG2 and MC4R on growth curves for adiposity in African- and European-American youth. Eur J Epidemiol. 2011;26(6):463-473.

12. Speliotes EK, Willer CJ, Berndt SI, et al. Association analyses of 249,796 individuals reveal 18 new loci associated with body mass index. Nat Genet. 2010;42(11):937-948.

13. Loos RJ, Rankinen T, Rice T, et al. Two ethnicspecific polymorphisms in the human Agouti-related protein gene are associated with macronutrient intake. Am J Clin Nutr. 2005;82(5):1097-1101. 